\title{
Correction to: Demography and population projection of Myzus persicae (Sulz.) (Hemiptera: Aphididae) on five pepper (Capsicum annuum L.) cultivars
}

\author{
Mehmet Salih Özgökçe • Hsin Chi • Remzi Atlıhan • \\ Hilmi Kara
}

Published online: 12 April 2018

(C) Springer Science+Business Media B.V., part of Springer Nature 2018

\section{Correction to: Phytoparasitica}

https://doi.org/10.1007/s12600-018-0651-0

Following publication of the above article (https://doi. org/10.1007/s12600-018-0651-0) Phytoparasitica (First Online: 20 February 2018), the following errors were found:

- Page 4: Right column, the fourth line beneath Eq. (12): "Eq. 3 can be written as" should be corrected to "Eq. 5 can be written as".

- Page 4: Left column, the second line beneath Eq. (13): "Eq. 11 can be simplified to" should be corrected to "Eq. 13 can be simplified to".

- Page 4: Left column, the third line beneath Eq. (14):

The term $\sum_{x=0}^{\infty} e^{-r(x+1)} l_{x, \text { alate }} m_{x, \text { alate }}=1$ should be corrected to $\sum_{x=0}^{\infty} e^{-r(x+1)} l_{x, \text { alate }} m_{x, \text { alate }}$.

The online version of the original article can be found at https://doi.org/10.1007/s12600-018-0651-0

M. S. Özgökçe $(\bowtie) \cdot$ R. Atlıhan · H. Kara

Faculty of Agriculture, Plant Protection Department, Van Yuzuncu Yil University, 65080 Van, Turkey

e-mail: msozgokce@yyu.edu.tr

H. Chi

Faculty of Agricultural Sciences and Technologies, Plant

Production and Technologies, Niğde Ömer Halisdemir University, Niğde, Turkey
- Page 8: Right column, the last paragraph: There are five "intrinsic rate". They should be corrected to "finite rate".

- Page 8: Right column, the sixth line in last paragraph: "ascendin" should be corrected to "ascending". The ninth line: "normal" should be corrected to "frequency".

- Page 9: First line: "Fig. 3" should be corrected to "Fig. 4".

- Page 9: Left column, the sixth line in the last paragraph: "Fig. 3" should be corrected to "Fig. 4".

- Page 10: In the figure caption: "Fig. 4" should be corrected to "Fig. 5".

- Page 11: First line: "Fig. 5" should be corrected to "Fig. 6".

- Page 12: First line: "Fig. 6. The total population size of Myzus persicae on different pepper cultivars." should be corrected to "Fig. 3. Top figure: The 200,000 finite rates ordered according to original bootstrap order ( $x$-axis). The 200,000 finite rates fluctuated randomly around the mean. Middle figure: The 200,000 finite rates sorted in ascending order. Bottom figure: The 200,000 finite rates shown as a frequency distribution. The 0.025 and 0.975 percentiles of finite rates can be obtained from the middle or bottom figures."

The authors wish to apologize for the errors within this article. 